\title{
Hydraulic Performance Modifications of a Zeolite Membrane after an Alkaline Treatment: Contribution of Polar and Apolar Surface Tension Components
}

\author{
Patrick Dutournié, Ali Said, T. Jean Daou, Jacques Bikaï, and Lionel Limousy \\ Institut de Science des Matériaux de Mulhouse (IS2M-UMR CNRS 7361), Université de Strasbourg, Université de Haute Alsace, \\ 3 bis rue A. Werner, 68093 Mulhouse Cedex, France \\ Correspondence should be addressed to Lionel Limousy; lionel.limousy@uha.fr
}

Received 7 December 2014; Revised 4 February 2015; Accepted 5 February 2015

Academic Editor: Peter Majewski

Copyright (C) 2015 Patrick Dutournié et al. This is an open access article distributed under the Creative Commons Attribution License, which permits unrestricted use, distribution, and reproduction in any medium, provided the original work is properly cited.

\begin{abstract}
Hydraulic permeability measurements are performed on low cut-off Na-mordenite (MOR-type zeolites) membranes after a mild alkaline treatment. A decrease of the hydraulic permeability is systematically observed. Contact angle measurements are carried out (with three polar liquids) on Na-mordenite films seeded onto alumina plates (flat membranes). A decrease of the contact angles is observed after the alkaline treatment for the three liquids. According to the theory of Lifshitz-van der Waals interactions in condensated state, surface modifications are investigated and a variation of the polar component of the material surface tension is observed. After the alkaline treatment, the electron-donor contribution (mainly due to the two remaining lone electron pairs of the oxygen atoms present in the zeolite extra frameworks) decreases and an increase of the electron-receptor contribution is observed and quantified. The contribution of the polar component to the surface tension is attributed to the presence of surface defaults, which increase the surface hydrophilicity. The estimated modifications of the surface interaction energy between the solvent (water) and the Na-mordenite active layer are in good agreement with the decrease of the hydraulic permeability observed after a mild alkaline treatment.
\end{abstract}

\section{Introduction}

Membrane processes are an interesting technology for the treatment or the separation of ionic and nonionic solutions. Many applications using membranes are commonly performed in industry as wastewater treatment [1], foodprocessing industry [2], or chemical and pharmaceutical operations $[3,4]$. One of the challenges of these next years is to develop membranes with specific filtration properties (for ionic rectification [5]) able to have several functionalities or properties, as, for example, bactericidal properties [6]. For this, mineral membranes and specially zeolite ones are very interesting. Indeed, zeolitic membranes are selective in size and shape and display various relevant properties depending on the zeolite nature or chemical composition. Numerous previous studies have shown that changes in the $\mathrm{Si} / \mathrm{Al}$ molar ratio and the internal or surface defects density have a significant effect on water interactions and transport with or within the zeolites [7-10].
The scientific community agrees to say that separation performances are functions of pore size, surface electric charge, and dielectric effects. These last ones deal with the confinement, the nature of the solvent, the nature of the surface, and the interactions between the solvent (or the solute) and the porous medium. The major difficulty is to measure and predict these effects. Indeed, the experimental estimation of these ones is not currently feasible. In many cases, they are estimated by indirect methods such as membrane potential experiments [11] or numerical investigations [12] obtained through the filtration of salt solutions with NF membranes. Nevertheless, the estimated result remains an average contribution (in the pore), acting on ionic solutes only.

Experimental results reported in the literature [13], which were obtained with zeolite membranes, show that these interactions can have a significant effect on membrane performances. Indeed, experimental tests carried out with ultrafiltration (low cut-off) membranes have shown that monovalent salts can be partially retained while an apolar solute (Vitamin B 
12) is completely transmitted. These observations can neither be explained by steric or electric effects nor be explained by influence of confinement. From this observation, the membrane performances can be explained only by the interactions between the membrane surface, the solvent, and the solute.

The purpose of this work is to investigate the modifications of these interactions after filtration of an alkaline solution. For this, contact angle measurements are performed on a flat Na-mordenite membrane to estimate the apolar and polar components of the surface tension.

\section{Experimental}

2.1. Membrane Preparation. $\alpha$-alumina plates $\left(2 \times 2 \mathrm{~cm}^{2}\right)$ were purchased from Rott, France. Alumina tubular supports (length $=25 \times 10^{-2} \mathrm{~m}$; internal diameter $=7 \times 10^{-3} \mathrm{~m}$ ) were provided by Pall Exekia (Bazet, France). Pretreatment of the substrates (alumina plates or tubes) was fully described by Lauridant and coauthors [14] and consists in cleaning the substrates in an aqueous solution of detergent (Alconox, $3 \mathrm{~g}$ in $400 \mathrm{~mL}$ of distilled water) heated to $60^{\circ} \mathrm{C}$ for $1 \mathrm{~h}$. They were then rinsed with distilled water, dried at $70^{\circ} \mathrm{C}$, and cooled down to ambient temperature.

A gel of Na-mordenite was prepared according to the operating procedure detailed by Hincapie et al. [15]. Starting from this gel, Na-MOR tubular membranes were produced by seeded hydrothermal synthesis onto the alumina tubular support. The spin coating process was used for the impregnation of the gel on the internal surface of the alumina tubes. The impregnated alumina tubes were then transferred in a $500 \mathrm{~mL}$ Teflon lined stainless steel autoclave (Top Industrie, France) and heated at $150^{\circ} \mathrm{C}$ for $42 \mathrm{~h}$. Five membranes were synthesized and calcined at different temperature $(\mathrm{M} 1$ at $300^{\circ} \mathrm{C}, \mathrm{M} 2$ at 300 and then at $400^{\circ} \mathrm{C}, \mathrm{M} 3$ and $\mathrm{M} 5$ at $400^{\circ} \mathrm{C}$, and $\mathrm{M} 4$ at $500^{\circ} \mathrm{C}$ ) for $2 \mathrm{~h}$.

In the case of the flat membranes synthesis two plates vertically fixed on a PTFE (Teflon) holder were immersed into the as-prepared Na-MOR-type zeolite gel, placed in $48 \mathrm{~mL}$ Teflon lined stainless steel autoclave (Top Industrie, France), and heated at $150^{\circ} \mathrm{C}$ for $42 \mathrm{~h}$. Na-mordenite crystals grew all over the surface of the plates and formed a homogeneous layer. These plates were used for contact angle measurements.

For comparison, a part of the gel was systematically reserved to produce Na-MOR-type zeolite powder. The flat and tubular membranes and the powder were simultaneously calcined between $300^{\circ} \mathrm{C}$ and $500^{\circ} \mathrm{C}$ for $4 \mathrm{~h}$. Hereafter the different obtained tubular membranes will be defined by a number going from 1 to 5 depending on the calcination temperature (Table 1).

2.2. Filtration Test Experiments. The filtration tests are carried out using a laboratory pilot-plant (T.I.A., Bollène, France) described in previous works and Na-mordenite tubular membranes (described above) $[12,13]$. Pure water filtration tests are performed by cross-flow rate experiments (constant flow rate of $700 \mathrm{~L} \mathrm{~h}^{-1}$ ) for various transmembrane pressures (volumetric pump). The fluid flow is controlled by an electromagnetic flow meter and pressure is measured by two sensors upstream and downstream of the membrane and the regulation is carried out by a manual valve. Experiments are carried out at $25^{\circ} \mathrm{C}$. The volume of the water tank is $5 \mathrm{~L}$. Pure water flux is measured for various transmembrane pressures $(\Delta P)$ in order to estimate membrane performances. Membrane hydraulic permeability can be expressed from a macroscopic point of view by

$$
J_{w}=\frac{L p}{\mu} \Delta P,
$$

where $J_{w}$ is the flux of water through the membrane and $\mu$ is the dynamic viscosity of water.

The hydraulic permeability is assessed by pure water filtration tests before and after each alkaline treatment.

2.3. Contact Angle Experiments. Contact angle $(\theta)$ measurements are performed with an OCA 15EC goniometer from DataPhysics Instruments $\mathrm{GmbH}$. The experiments are carried out with three different liquids (distilled water, glycerol, and ethylene glycol) in order to determine disperse and polar surface energies with the OWRK method (Owens, Wendt, Rabel, and Kaelble) [16]. All the plates are hydrated or put in contact with the alkaline solution $\left(\mathrm{Na}_{2} \mathrm{CO}_{3}, 6.6 \mathrm{mM}, \mathrm{pH}\right.$ $=10.8$ ) for $2 \mathrm{~h}$ at $25^{\circ} \mathrm{C}$ and then rinsed with distilled water to evacuate the carbonate ions, before being dried at $60^{\circ} \mathrm{C}$ for $48 \mathrm{~h}$.

Supplementary experiments were performed with $\alpha$ alumina plates without $\mathrm{Na}$-mordenite to estimate the contribution of the support. All the experiments showed that the liquids immediately penetrate the porous medium due to the high macroporosity of the support. Then, the influence of the support on the measurement of the surface energy can be neglected.

2.4. Characterizations. The $\mathrm{Si} / \mathrm{Al}$ molar ratio of the $\mathrm{Na}-$ mordenite layers coated on the plates was achieved by X-ray wavelength fluorescence (XRF) measurements, performed with a MagiX Philips $(2.4 \mathrm{~kW})$ apparatus. The morphology of the Na-mordenite crystals present at the surface of the $\alpha$ alumina plates and the homogeneity and the thickness of the $\mathrm{Na}$-mordenite layer were performed with a scanning electron microscope (Philips XL 30 FEG).

\section{Results and Discussion}

Previous investigations carried out with $\mathrm{Na}$-mordenite membranes have shown that their filtration properties are deeply modified after an alkaline treatment. Indeed, no salt rejection was observed during filtration tests of pure salt-water solutions ( $5 \mathrm{mM}$ of $\mathrm{NaCl}, \mathrm{NaF}, \mathrm{Na} \mathrm{Br}, \mathrm{NaI}$, and $\mathrm{Na}_{2} \mathrm{SO}_{4}$ ). After the alkaline treatment (filtration of a $6.6 \mathrm{mM} \mathrm{Na}_{2} \mathrm{CO}_{3}$ solution at $\mathrm{pH}=10.8$ for 2 hours), ion rejection rates are more and less significant $[13,17]$.

In these works the modification of the membrane properties (in terms of salt rejections) was attributed to a modification of the surface polarity [18] and more precisely to the modifications of the van der Waals forces (London, Keesom and Debye interactions) and Lewis-Brönsted acidbase interactions. For short distances $(d<10 \mathrm{~nm})$, these interactions decrease with distance as $d^{-2}$ [19] and as $d^{-3}$ 
TABLE 1: Evaluation of the hydraulic permeability from pure water filtration tests performed before and after an alkaline treatment.

\begin{tabular}{lcccc}
\hline Membrane & $\begin{array}{c}T \text { calcination } \\
\left({ }^{\circ} \mathrm{C}\right)\end{array}$ & $\begin{array}{c}\text { Hydraulic permeability } \\
\left(\mathrm{m}^{3} \mathrm{~m}_{\mathrm{memb}}^{-2}\right)\end{array}$ & Nature of the treatment & $\begin{array}{c}\text { Hydraulic permeability } \\
\left(\mathrm{m}^{3} \mathrm{~m}_{\mathrm{memb}}^{-2}\right)\end{array}$ \\
\hline M1 & 300 & $2.7 E-14$ & $\mathrm{Na}_{2} \mathrm{CO}_{3}-6.6 \mathrm{mM}$ & $1.8 E-14$ \\
M2 & $300 \& 400$ & $8.8 E-15$ & $\mathrm{Na}_{2} \mathrm{CO}_{3}-6.6 \mathrm{mM}$ & $7.6 E-15$ \\
M3 & 400 & $3.6 E-14$ & $\mathrm{Na}_{2} \mathrm{CO}_{3}-6.6 \mathrm{mM}$ & $2.74 E-14$ \\
M4 & 500 & $5.3 E-14$ & $\mathrm{NaOH}^{2}-1 \mathrm{mM}$ & $4.77 E-14$ \\
M5 & 400 & $4.6 E-14$ & $\mathrm{Na}_{2} \mathrm{CO}_{3}-6.6 \mathrm{mM}$ & 0.86 \\
& & Tests performed after two acid $[\mathrm{HCl}-12 \mathrm{mM}] /$ base treatments for $\mathrm{M} 3$ & 0.90 \\
M3 & 400 & $10.2 E-14$ & $\mathrm{Na}_{2} \mathrm{CO}_{3}-6.6 \mathrm{mM}$ & $5.7 E-14$ \\
M3 & 400 & $5.0 E-14$ & $\mathrm{Na}_{2} \mathrm{CO}_{3}-6.6 \mathrm{mM}$ & $3.9 E-14$ \\
\hline
\end{tabular}

beyond $10 \mathrm{~nm}[20,21]$. The investigation of the surface thermodynamics of acid-base interactions (Lewis-Brönsted) was recently performed by studying the surface acidity of $\mathrm{Na}$ mordenite [22]. The results show a significant modification of the surface chemistry of the Na-mordenite crystals after the mild alkaline treatment explained by the transformation of some Brönsted surface sites $|\mathrm{H}|[\mathrm{Al}-\mathrm{Si}-\mathrm{O}]$ into pseudo-Lewis acid sites $|\mathrm{Na}+|[\mathrm{Al}-\mathrm{O}-]$ after silicon extraction.

All these observations lead to the hypothesis that after the alkaline treatment, the surface polarity of the Na-mordenite crystals increases significantly. This should modify the transfer of pure solvent. In order to confirm the presence of significant interactions between water molecules and the surface of the Na-MOR-type zeolite crystals after the alkaline treatment, pure water filtration tests were carried out on different Na-mordenite tubular membranes. Figure 1 shows the experimental results obtained for two membranes (1 and 5) before and after the alkaline treatment. The slope of each experimental series corresponds to the hydrodynamic permeability $(L p)$ of the membrane.

Hydraulic permeabilities of different Na-MOR-type zeolite membranes are reported in Table 1 . In the first part of Table 1, we present the evolution of the hydraulic permeabilities induced by an alkaline treatment performed just after the conditioning step [23]. At the bottom of Table 1 we show the evolution of the hydraulic permeability of M3 after two acid/base treatments (filtration of a $\mathrm{HCl}$ solution $1 \mathrm{mM}$ during 2 hours, rinsing with pure water, and filtration of a sodium carbonate solution at a concentration of $6.6 \mathrm{mM}$ ). An estimation of the membrane pore radius has been systematically performed by filtration of a neutral compound (Vitamin B 12) after the alkaline treatments in order to observe an eventual modification of the pore size [24].

The results indicate systematically a drop of the hydraulic permeability without a decrease of the membrane porosity (constant rejection of $\mathrm{VB} 12$ ) and, at the same time, we observe a partial rejection of the salts mentioned above after the alkaline treatment. It is known that an alkaline treatment could be at the origin of mesopore formation in zeolites when it is performed at high concentration $[25,26]$. Nevertheless, the alkaline treatment we use is a mild one, which may only induce a modification of the mordenite surface crystals.

Some authors have used the extended solution-diffusion model to describe the volumetric flux obtained during the filtration of water. This model initially developed for nonporous

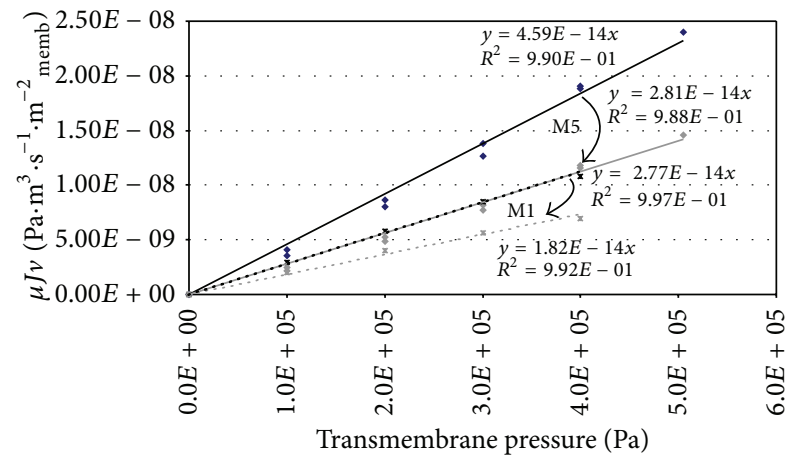

FIGURE 1: Extraction of the hydraulic permeabilities of different zeolite tubular membranes from the representation of the permeation flux versus the transmembrane pressure (membranes 1 (dotted lines) and 5 (full lines) before (black) and after the alkaline treatment (grey)).

membrane has been modified to describe the transfer of water through NF/RO porous membranes [27].

In this way, the volumetric flux can be expressed as for pure water by the following [28]:

$$
J_{w}=\frac{K_{d} D_{w}^{\infty} \varepsilon}{\Delta x}\left(1-\lambda_{w}\right)^{2} \exp \left(-\frac{\left|\Delta G_{w}\right|}{k_{B} T}\right) \frac{V_{w}}{R T} \Delta P,
$$

where $K_{d} D_{w}^{\infty}$ is the diffusion coefficient of water in the porous media, $\varepsilon / \Delta x$ the ratio between porosity and thickness of the active layer, $\left(1-\lambda_{w}\right)^{2}=\left(1-r_{w} / r_{p}\right)^{2}$ the steric exclusion (ratio between stokes radius of water and pore radius), $V_{w}$ the molar volume, $\Delta P$ the transmembrane pressure, $R$ the gas constant, $T$ the temperature, $k_{B}$ the Boltzmann constant, and $\Delta G_{w}$ the water-membrane surface interaction energy.

There is no reason why the mild alkaline treatment leads to a decrease of the active layer thickness as well as the pore size distribution of the Na-mordenite layer (no modification of Vitamin B 12 transmission). The only way to explain the drop of permeability is a modification of the water-surface interaction energy. Indeed, the ratio of the water fluxes before $\left(J_{1, w}\right)$ and after treatment $\left(J_{2, w}\right)$ is given by

$$
\frac{J_{1, w}}{J_{2, w}}=\exp \left(-\frac{\left(\left|\Delta G_{1, w}\right|-\left|\Delta G_{2, w}\right|\right)}{k_{B} T}\right) .
$$


TABle 2: Apolar (Lifshitz-van der Waals) and polar (Lewis acid-base: electron-acceptor and electron-donor contributions) surface tension components $\left(\mathrm{mN} \mathrm{m}^{-1}\right)$ for water, ethylene glycol, and glycerol.

\begin{tabular}{|c|c|c|c|c|c|c|c|c|c|}
\hline & \multicolumn{3}{|c|}{ Water } & \multicolumn{3}{|c|}{ Glycerol } & \multicolumn{3}{|c|}{ Ethylene glycol } \\
\hline & \multirow{2}{*}{$\gamma_{L}^{\mathrm{LW}}$} & \multicolumn{2}{|c|}{$\gamma_{L}^{\mathrm{AB}}$} & \multirow{2}{*}{$\gamma_{L}^{\mathrm{LW}}$} & \multicolumn{2}{|c|}{$\gamma_{L}^{\mathrm{AB}}$} & \multirow{2}{*}{$\gamma_{L}^{\mathrm{LW}}$} & \multicolumn{2}{|c|}{$\gamma_{L}^{\mathrm{AB}}$} \\
\hline & & $\left(\gamma_{L}^{+}\right)$ & $\left(\gamma_{L}^{-}\right)$ & & $\left(\gamma_{L}^{+}\right)$ & $\left(\gamma_{L}^{-}\right)$ & & $\left(\gamma_{L}^{+}\right)$ & $\left(\gamma_{L}^{-}\right)$ \\
\hline Jańczuk et al. [29] & 21.8 & 25.5 & 25.5 & 33.6 & 9.89 & 22.3 & 31.5 & 5.98 & 11.6 \\
\hline Costanzo et al. [30] & 21.8 & 25.5 & 25.5 & 34 & 3.92 & 57.4 & 29 & 3 & 30.1 \\
\hline Lee $[31]$ & 21.8 & 34.2 & 19 & 34 & 5.30 & 42.5 & 29 & 2.6 & 34.8 \\
\hline
\end{tabular}

As $J_{1, w}$ is higher than $J_{2, w}$, it means that the interaction energy between water and the membrane surface has increased after the alkaline treatment. The rise of the interaction energy should be experimentally expressed by an increase of the surface tension or a decrease of the contact angle.

According to the theory of Lifshitz-van der Waals interactions in condensated state [32-34], the interaction energy between water molecules and a surface $\Delta G_{w}$ (the membrane surface in the present case) can be related to surface tension via the Young-Dupré equation:

$$
\Delta G_{w}=-A_{w s}(1+\cos \theta) \gamma_{w}
$$

where $A_{w s}$ is the contact area between the water molecule and the membrane surface, $\gamma_{w}$ is the apparent surface tension of water, and $\theta$ is the contact angle between the water drop and the Na-mordenite surface.

As it was previously described, these interactions are the sum of two components: the apolar Lifshitz-van der Waals interactions (LW) and the polar interactions due to the presence of hydrogen bonding [35]. The set of these interactions (hydrogen bonding) are often called Lewis acid-base (AB) interactions.

From this hypothesis, the apparent surface tension (or the interaction energy) can be expressed as the sum of two contributions:

$$
\gamma=\gamma^{\mathrm{LW}}+\gamma^{\mathrm{AB}}
$$

If the apolar interactions (Lifshitz-van der Waals) are symmetrical, the polar interactions (AB) are essentially asymmetrical. To take into account this asymmetry, two polar components of the surface tension are defined: an electron acceptor $\gamma^{+}$and an electron donor $\gamma^{-}$[36].

The Young-Dupré equation can be expressed for a liquid $(L)$ in contact with a surface $(S)$ by (6) derived from the van Oss et al. approach [34]:

$$
\begin{aligned}
\Delta G & =\Delta G^{\mathrm{LW}}+\Delta G^{\mathrm{AB}}=-A_{L S}(1+\cos \theta) \gamma \\
& =-2 A_{L S}\left(\sqrt{\gamma_{S}^{\mathrm{LW}} \gamma_{L}^{\mathrm{LW}}}+\sqrt{\gamma_{S}^{+} \gamma_{L}^{-}}+\sqrt{\gamma_{S}^{-} \gamma_{L}^{+}}\right) .
\end{aligned}
$$

First, by a single contact angle measurement with the studied liquid, the apparent interaction energy can be estimated. Second, by contact angle measurements performed with three liquids (presenting distinct polarities), the different contributions of the surface tension can be estimated by solving (6) for the three liquids. For each liquid, this requires the knowledge of apolar and polar components of the surface tension. In this work, we choose to use water, ethylene glycol, and glycerol as references for the contact angle measurements in order to solve (6). Table 2 lists apolar and polar contributions of the surface tension for these liquids, extracted from the literature. The values of polar contributions (electronacceptor and electron-donor) available in the literature are very different. Taking into account these significant differences, the calculations are performed with three sets of data from three different sources.

SEM investigations were performed on the Na-mordenite plates. The aim of these characterizations was to evaluate the behavior of the Na-mordenite crystal present at the surface of the plates after hydration or alkaline treatment. SEM images corresponding to the hydrated and treated plates are presented in Figure 2. The observation of the plate surface after an alkaline treatment (Figure 2(c)) indicates that the Namordenite crystals remain agglomerated and no modification of the surface is observed.

At a higher enlargement (Figures 2(b) and 2(d)) we can see that the external texture of the Na-mordenite crystals seems to be different after the alkaline treatment (Figure $2(\mathrm{~d})$ ). The $\mathrm{Si} / \mathrm{Al}$ molar ratio of Na-mordenite was determined by XRF spectroscopy and seems to slightly decrease after the alkaline treatment $(\mathrm{Si} / \mathrm{Al}=5.85$ before the treatment and 5.78 after the treatment). It means that silicon atoms are extracted from the surface of the Na-MORtype zeolite, as suggested by the modification of the external texture observed by SEM (Figure 2(d)).

The contact angles obtained with the three liquids are presented in Table 3. We observe a significant decrease of the contact angles for the treated $\mathrm{Na}$-mordenite plates whatever the liquid is. The estimated surface tension is very close to the one of pure water (72.3 versus $72.8 \mathrm{~m} \mathrm{~N} \mathrm{~m}^{-1}$ for water) for the untreated Na-mordenite plate.

From (6), we obtain an equation with three variables for each liquid. The solvation of the equation set leads to the estimation of $\gamma_{s}^{\mathrm{LW}}, \gamma_{s}^{+}$, and $\gamma_{s}^{-}$(before and after the alkaline treatment). Table 4 summarizes the estimated values for the apolar and the polar components of the surface tension.

Even if the polar components of the surface tension are different according to the source we used [29-31], the results we obtained show the same tendencies for the three references. The calculations show that the apolar component (Lifshitz-Van der Waals) is very little. Before the alkaline treatment, the polar component corresponds in major part to 


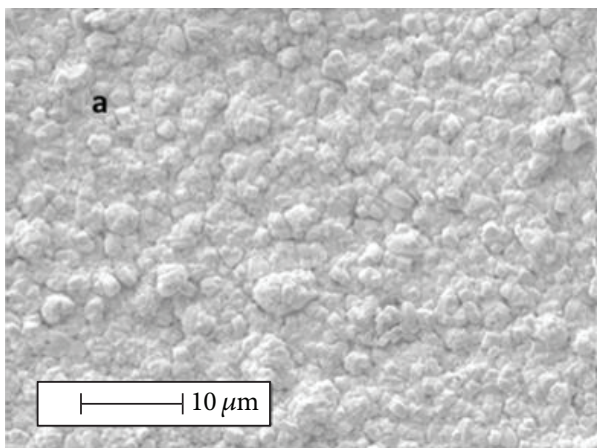

(a)

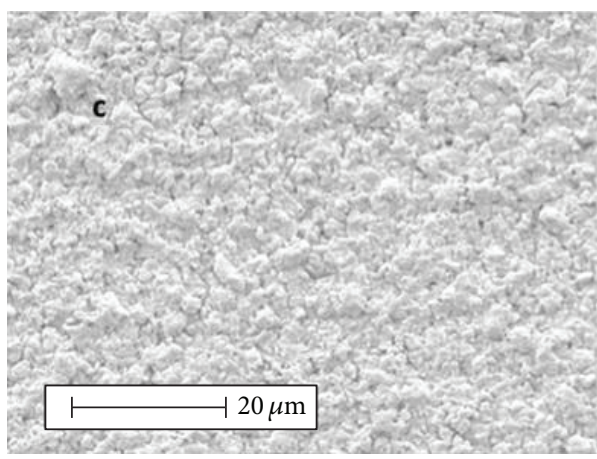

(c)

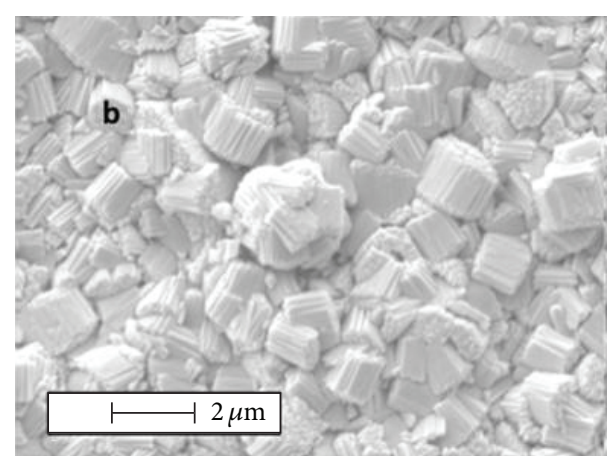

(b)

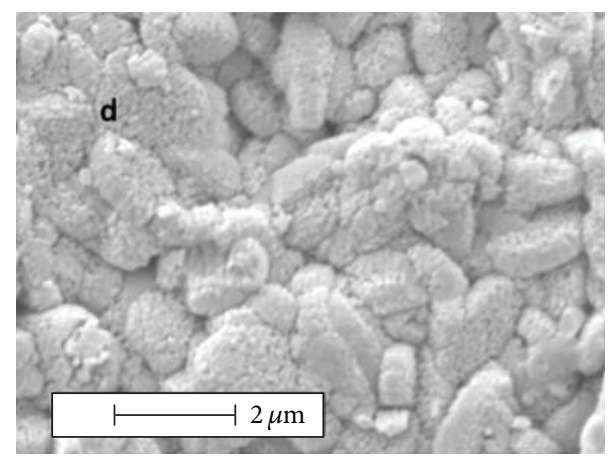

(d)

FIGURE 2: SEM photographs of the hydrated ((a) and (b)) and the treated Na-mordenite plates obtained at different enlargement ((c) and (d)).

TABLE 3: Estimation of the surface tension of the treated and the nontreated Na-mordenite plates from the contact angles obtained with water, ethylene glycol, and glycerol.

\begin{tabular}{lcccc}
\hline & \multicolumn{2}{c}{ Before alkaline treatment } & \multicolumn{2}{c}{ After alkaline treatment } \\
& $\begin{array}{c}\gamma \\
\left(\mathrm{mN} \mathrm{m}^{-1}\right)\end{array}$ & $\begin{array}{c}\theta \\
(\text { degree })\end{array}$ & $\begin{array}{c}\gamma \\
\left(\mathrm{mN} \mathrm{m}^{-1}\right)\end{array}$ & $\begin{array}{c}\theta \\
(\text { degree })\end{array}$ \\
\hline Water & - & 18.6 & - & 9.5 \\
$\begin{array}{l}\text { Glycerol } \\
\text { Ethylene }\end{array}$ & - & 33.1 & - & 23 \\
glycol & - & 20.4 & - & 15.2 \\
& 72.3 & & 77 & \\
\hline
\end{tabular}

the electron-donor contribution of the Lewis acid-base interactions. This is mainly due to the presence of two remaining lone pairs of electrons on the oxygen atoms present at the surface of the zeolite crystals. After the alkaline treatment, some silicon atoms are extracted from the extra framework of the zeolite that induces the apparition of surface defaults corresponding in major part to pseudo-Lewis acid sites and then surface hydroxyl groups. This modification of the surface properties induces an increase of electron-acceptor contribution in the polar component of the surface tension.

The calculation of $\Delta G_{w}$ (the water-membrane surface interaction energy) shows an increase of interaction energy (in absolute value) after the alkaline treatment: $\Delta G_{w}^{1}=-5.95$ $\times 10^{-21} \mathrm{~J}$ and $\Delta G_{w}^{2}=-6.46 \times 10^{-21} \mathrm{~J}$, respectively. The ratio of water flux after and before the treatment (or the hydraulic permeability modification) calculated using (3) is 0.88 . This result is comparable with the observed permeability drop obtained with the five membranes, which is in the range 0.60.9 .

\section{Conclusion}

Experimental filtration tests were performed with pure water before and after a mild alkaline treatment. The hydraulic permeabilities of the different membranes synthesized for this study decrease after the treatment. These observations cannot be explained by a modification of the pore size. Only a modification of the surface interactions between the material and the solvent can explain these results. Contact angle measurements are performed on flat mordenite membranes to investigate the effect of the alkaline treatment. These results are analyzed according to the Lifshitz-van der Waals theory of surface tension. The apolar and polar components of the surface material are estimated. The results show that the major contribution is the polar component and more precisely the electron-donor contribution. After the alkaline treatment, an increase of electron-receptor contribution in the polar component of the tension surface is observed probably due to the presence of surface defaults that increases significantly the surface hydrophilicity.

The water-membrane surface interaction energies are deduced from this investigation and allow the explanation 
TABLE 4: Estimation of the surface tension components $\left(\mathrm{mN} \mathrm{m}^{-1}\right)$ of the Na-mordenite layer from the contact angle measurements obtained with three liquids (Table 3).

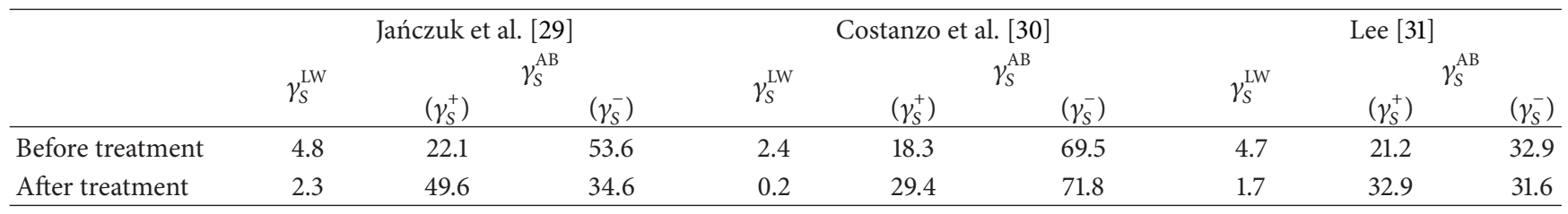

and the quantification of water flux to decrease after a mild alkaline treatment.

\section{Conflict of Interests}

The authors declare that there is no conflict of interests regarding the publication of this paper.

\section{References}

[1] K. E. Geckeler and K. Volchek, "Removal of hazardous substances from water using ultrafiltration in conjunction with soluble polymers," Environmental Science and Technology, vol. 30, no. 3, pp. 725-733, 1996.

[2] D. Knorr, A. Froehling, H. Jaeger, K. Reineke, O. Schlueter, and K. Schoessler, "Emerging technologies in food processing," Annual review of food science and technology, vol. 2, pp. 203-235, 2011.

[3] L. Peeva, J. da Silva Burgal, I. Valtcheva, and A. G. Livingston, "Continuous purification of active pharmaceutical ingredients using multistage organic solvent nanofiltration membrane cascade," Chemical Engineering Science, vol. 116, pp. 183-194, 2014.

[4] C. H. Vogel and C. M. Todaro, Fermentation and Biochemical Engineering Handbook, Elsevier, Waltham, Mass, USA, 3rd edition, 2014.

[5] R. Malaisamy, A. Talla-Nwafo, and K. L. Jones, "Polyelectrolyte modification of nanofiltration membrane for selective removal of monovalent anions," Separation and Purification Technology, vol. 77, no. 3, pp. 367-374, 2011.

[6] A. Nagy, A. Harrison, S. Sabbani, R. S. Munson Jr., P. K. Dutta, and W. J. Waldman, "Silver nanoparticles embedded in zeolite membranes: release of silver ions and mechanism of antibacterial action," International Journal of Nanomedicine, vol. 6, pp. 1833-1852, 2011.

[7] V. Eroshenko, R.-C. Regis, M. Soulard, and J. Patarin, "Energetics: a new field of applications for hydrophobic zeolites," Journal of the American Chemical Society, vol. 123, no. 33, pp. 8129-8130, 2001.

[8] I. Khay, T. J. Daou, H. Nouali, A. Ryzhikov, S. Rigolet, and J. Patarin, "High pressure intrusion-extrusion of $\mathrm{LiCl}$ aqueous solutions in silicalite-1 zeolite: influence on Energetic performances," Journal of Physical Chemistry C, vol. 118, no. 8, pp. 3935-3941, 2014.

[9] Z. E. Hughes, L. A. Carrington, P. Raiteri, and J. D. Gale, "A computational investigation into the suitability of purely siliceous zeolites as reverse osmosis membranes," Journal of Physical Chemistry C, vol. 115, no. 10, pp. 4063-4075, 2011.

[10] J. Caro, S. Hocevar, J. Kärger, and L. Riekert, "Intracrystalline self-diffusion of $\mathrm{H}_{2} \mathrm{O}$ and $\mathrm{CH}_{4}$ in ZSM-5 zeolites," Journal of Colloids and Surfaces A, vol. 6, pp. 213-216, 1986.
[11] A. Escoda, Y. Lanteri, P. Fievet, S. Déon, and A. Szymczyk, "Determining the dielectric constant inside pores of nanofiltration membranes from membrane potential measurements," Langmuir, vol. 26, no. 18, pp. 14628-14635, 2010.

[12] P. Dutournié, L. Limousy, N. Zouaoui, H. Mahzoul, and E. Chevereau, "Facilitated transport of monovalent salt mixture through ultrafiltration Na-Mordenite membrane: numerical investigations of electric and dielectric contributions," Desalination, vol. 280, no. 1-3, pp. 397-402, 2011.

[13] E. Chevereau, L. Limousy, and P. Dutournié, "Use of Mordenite surface acidity properties for the selective separation of halide salts: modification of dielectric effects," Industrial and Engineering Chemistry Research, vol. 50, no. 7, pp. 4003-4010, 2011.

[14] N. Lauridant, T. J. Daou, G. Arnold et al., "Key steps influencing the formation of ZSM-5 films on aluminum substrates," Microporous and Mesoporous Materials, vol. 152, pp. 1-8, 2012.

[15] B. O. Hincapie, L. J. Garces, Q. Zhang, A. Sacco, and S. L. Suib, "Synthesis of mordenite nanocrystals," Microporous and Mesoporous Materials, vol. 67, no. 1, pp. 19-26, 2004.

[16] Y.X. Zhuang and O. Hansen, "Correlation of effective dispersive and polar surface energies in heterogeneous self-assembled monolayer coatings," Langmuir, vol. 25, no. 10, pp. 5437-5441, 2009.

[17] P. Dutournié, L. Limousy, W. Blel, S. Déon, and P. Fievet, "Understanding of ion transport in a na-mordenite membrane: use of numerical modeling to estimate surface-solute interactions in the pore," Industrial and Engineering Chemistry Research, vol. 53, no. 19, pp. 8221-8227, 2014.

[18] C. J. van Oss and R. F. Giese, “The hydrophilicity and hydrophobicity of clay minerals," Clays and Clays Minerals, vol. 43, no. 4, pp. 474-477, 1995.

[19] H. C. Hamaker, "The London-van der Waals attraction between spherical particles," Physica, vol. 4, no. 10, pp. 1058-1072, 1937.

[20] H. R. Kruyt, G. H. Jonker, and J. T. G. Overbeek, Colloid Science Volume 1: Irreversible Systems, Elsevier, Amsterdam, The Netherlands, 1952.

[21] H. B. G. Casimir and D. Polder, "The influence of retardation on the London-van der Waals forces," Physical Review, vol. 73, no. 4, pp. 360-372, 1948.

[22] L. Limousy, P. Dutournié, and E. Chevereau-Landais, "Description of the preferential transport of monovalent salts through Na-mordenite membrane: physico-chemical aspects," Microporous and Mesoporous Materials, vol. 167, pp. 133-136, 2013.

[23] J. Bikaï, L. Limousy, P. Dutournié, L. Josien, and W. Blel, "Stabilisation of the water permeability of mineral ultrafiltration membranes: an empirical modelling of surface and pore hydration," Comptes Rendus Chimie, vol. 18, no. 1, pp. 56-62, 2015. 
[24] W. R. Bowen, A. W. Mohammad, and N. Hilal, "Characterisation of nanofiltration membranes for predictive purposesuse of salts, uncharged solutes and atomic force microscopy," Journal of Membrane Science, vol. 126, no. 1, pp. 91-105, 1997.

[25] S. Huang, X. Liu, L. Yu et al., "Preparation of hierarchical mordenite zeolites by sequential steaming-acid leaching-alkaline treatment," Microporous and Mesoporous Materials, vol. 191, pp. 18-26, 2014.

[26] A. N. C. van laak, R. W. Gosselink, S. L. Sagala, J. D. Meeldijk, P. E. de Jongh, and K. P. de Jong, "Alkaline treatment on commercially available aluminum rich mordenite," Applied Catalysis A: General, vol. 382, no. 1, pp. 65-72, 2010.

[27] J. Wang, Y. Mo, S. Mahendra, and E. M. V. Hoek, "Effects of water chemistry on structure and performance of polyamide composite membranes," Journal of Membrane Science, vol. 452, pp. 415-425, 2014.

[28] J. Wang, D. S. Dlamini, A. K. Mishra et al., "A critical review of transport through osmotic membranes," Journal of Membrane Science, vol. 454, pp. 516-537, 2014.

[29] B. Jańczuk, W. Wójcik, and A. Zdziennicka, "Determination of the components of the surface tension of some liquids from interfacial liquid-liquid tension measurements," Journal of Colloid And Interface Science, vol. 157, no. 2, pp. 384-393, 1993.

[30] P. M. Costanzo, R. F. Giese, and C. J. van Oss, "Determination of the acid-base characteristics of clay mineral surfaces by contact angle measurements-implications for the adsorption of organic solutes from aqueous media," Journal of Adhesion Science and Technology, vol. 4, no. 1, pp. 267-275, 1990.

[31] L.-H. Lee, "Correlation between Lewis acid-base surface interaction components and linear solvation energy relationship solvatochromic $\alpha$ and $\beta$ parameters," Langmuir, vol. 12, no. 6 , pp. 1681-1687, 1996.

[32] I. E. Dzyaloshinskii, E. M. Lifshitz, and L. P. Pitaevskii, "The general theory of van der Waals forces," Advances in Physics, vol. 10, pp. 165-209, 1961.

[33] V. A. Parsegian and B. W. Ninham, "Van der Waals forces in many-layered structures: generalizations of the Lifshitz result for two semi-infinite media," Journal of Theoretical Biology, vol. 38, no. 1, pp. 101-109, 1973.

[34] C. J. van Oss, M. K. Chaudhury, and R. J. Good, "Interfacial Lifshitz-van der Waals and polar interactions in macroscopic systems," Chemical Reviews, vol. 88, no. 6, pp. 927-941, 1988.

[35] C. J. van Oss, R. J. Good, and M. K. Chaudhury, "The role of van der Waals and hydrogen bonds in 'hydrophobic interactions' between biopolymers and low energy surfaces," Journal of Colloid and Interface Science, vol. 111, no. 2, pp. 378-390, 1985.

[36] W. Wu, R. F. Giese Jr., and C. J. van Oss, "Evolution of the Lifshitz-van der Waals/acid-base approach to determine surface tension components," Langmuir, vol. 11, no. 1, pp. 379-382, 1995. 

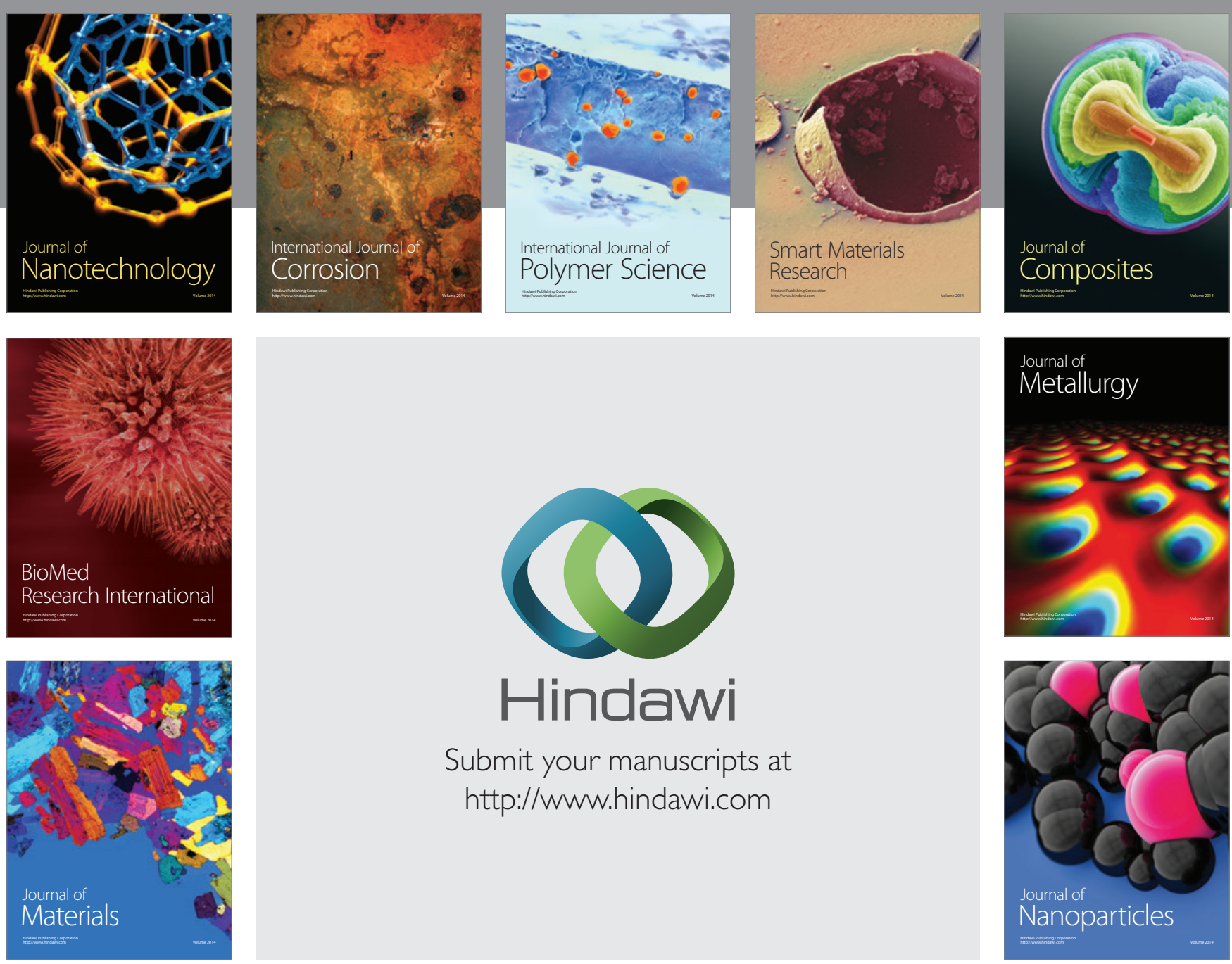

Submit your manuscripts at http://www.hindawi.com
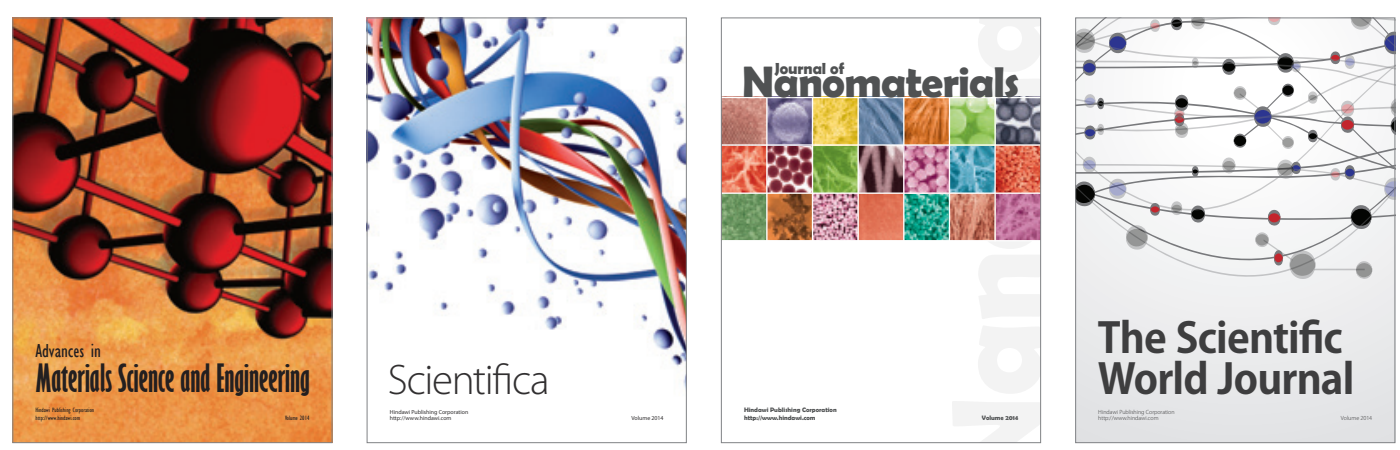

\section{The Scientific World Journal}
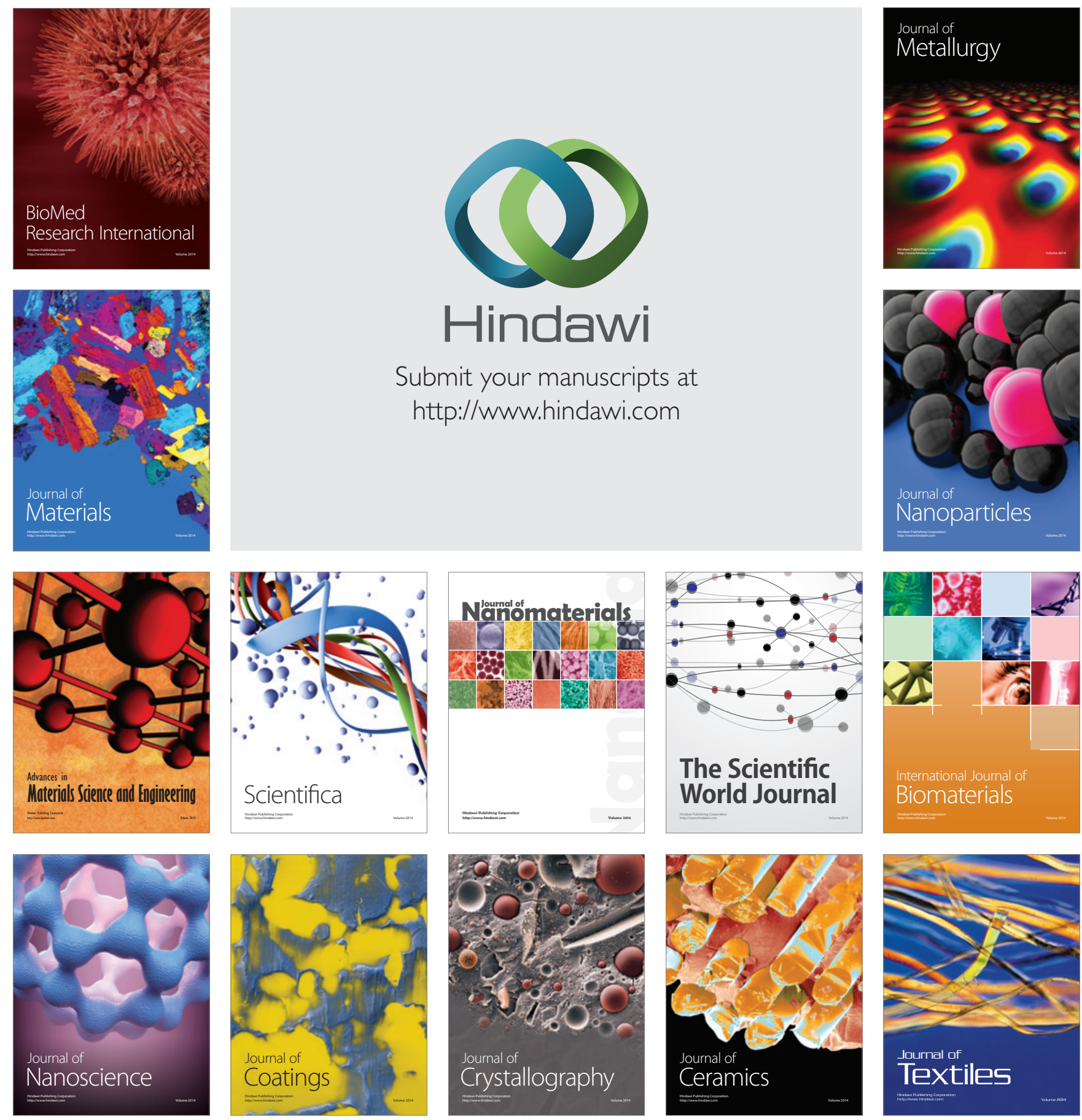